\title{
Philip Morris International's use of Facebook to undermine Australian tobacco control laws
}

\author{
Becky Freemana,e, Marita Hefler ${ }^{b}$, Daniel Hunt ${ }^{\mathrm{c}}$ \\ a School of Public Health, Sydney Medical School, University of Sydney, NSW, Australia \\ b Wellbeing and Preventable Chronic Disease, Menzies School of Health Research, Darwin, NT, Australia \\ c Independent Health Policy Consultant, Melbourne, VIC, Australia \\ e Corresponding author: becky.freeman@sydney.edu.au
}

\section{Article history}

Publication date: September 2019

Citation: Freeman B, Hefler M, Hunt D.

Philip Morris International's use of

Facebook to undermine Australian Tobacco

control laws. Public Health Res Pract.

2019;29(3):e2931924.

https://doi.org/10.17061/phrp2931924

\section{Background}

The World Health Organization (WHO) Framework Convention on Tobacco Control (FCTC) ${ }^{1}$ requires all ratifying parties to implement comprehensive bans on all forms of tobacco advertising, promotion and sponsorship, including online media, and to protect public health polices from tobacco industry interference. However, the borderless nature of the internet, coupled with narrow definitions of advertising and interference, means the tobacco industry still uses online and social media to sell and promote its products, highlight supposed corporate social responsibility practices, and challenge public health views and policies. ${ }^{2}$

\section{A "smoke-free future"}

Philip Morris International (PMI), one of the largest global cigarette companies, is also using social media as a key component of its claimed transformation to a "smoke-free future". One pillar of this effort is the 2017 launch of the PMI-created and fully funded Foundation for a Smoke-Free World, which has been shown to be little more than a public relations campaign. ${ }^{3}$ Although the Foundation claims to be independent and aimed at ending smoking, this envisioned "smoke-free future" is deeply pegged to the sales and marketing of PMI's heated tobacco product, IQOS. PMI also has a range of electronic nicotine products, available in the UK, which it terms the "next generation of e-vapour technology". ${ }^{4}$ The IQOS device is distinct from electronic cigarettes (e-cigarettes) in that it heats up tobacco sticks, rather than creating a vapour from nicotine-containing liquid. PMI has used IQOS to engage with government officials and attempt to position themselves as partners in tobacco control. ${ }^{5}$ Australia currently prohibits the sale of both nicotine-containing electronic e-cigarettes and heated tobacco products. However, the PMI strategy is consistent with the tobacco industry's long history of interference in health policy making. ${ }^{6}$ 


\section{Push to weaken Australian}

\section{tobacco laws}

The PMI Facebook page, with 1.39 million global followers as of June 2019, is a moderated page with the stated purpose to: "Foster conversations around who we are, what we do and what it is like to work at PMI. It has not been created to market, advertise or promote our products, brands or securities."7 The page is geotargeted, with users defaulting to receive tailored content depending on the country in which they access Facebook. Users can also choose to select their preferred content feed from a list of 45 countries for which PMI creates custom content, or to opt to view the general feed if there is no specific country feed available. In April 2019, PMI created a specific feed, @pmiaustralia, for its Australian Facebook users. ${ }^{8}$ An analysis of the first month of Australian-specific posts reveals that PMI, contrary to its stated purpose, primarily used the page to lobby for the relaxation of regulations that currently prevent its IQOS tobacco products from being sold in Australia. (See Table 1).

Table 1. Summary of PMI Australia Facebook posts 30 April-30 May 2019

\begin{tabular}{lc}
\hline Topic of post & $\%(n)$ \\
\hline Relax Australian vaping product laws & $64(16)$ \\
PMI corporate practices & $20(5)$ \\
PMI smoke-free future vision & $8(2)$ \\
Gender equality & $4(1)$ \\
Illicit tobacco use increasing & $4(1)$ \\
\hline Total & $100(25)$ \\
\hline a Posts refer to PMI Australia receiving a Workplace Gender Equality \\
Agency award
\end{tabular}

Three of the posts that argued the Australian Government should relax vaping product laws included links to media reports about published academic journal articles that posited the benefits of using e-cigarettes for smoking cessation. None of the cited studies specifically mentioned or tested the IQOS device, nor did PMI clarify that its IQOS product was distinct from e-cigarettes. One post also included a link to an Australasian Association of Convenience Stores survey that claimed support for legalising e-cigarette sales in Australia was increasing, with no mention that the tobacco industry is a long-time partner of the Association. ${ }^{9}$

In addition to linking to selected research to support its case for relaxation of vaping product laws, the PMI Facebook page also included posts with links to official government bodies, including: four posts to the 30 April 2019 US Food and Drug Administration (FDA) ruling allowing IQOS products to be legally sold in the US, and two posts to Australian Government departments the Workplace Gender Equality Agency (WEGA) and Australian Border Force (ABF). Posts linked to the US FDA ruling suggested Australia needed to "catch up to the rest of the of world" in legalising all e-cigarette sales. This ignores the fact that many countries currently ban or strictly regulate e-cigarettes and heated tobacco products; the sale of all types of e-cigarettes is banned in 29 countries and a further six countries ban nicotinecontaining devices. ${ }^{10}$ The PMI link to WEGA was in relation to the fact that the Agency has awarded PMI a workplace gender equality citation annually since 2016. This is despite Australia being a party to the WHO FCTC, which obliges governments to only interact with the tobacco industry when strictly necessary to aid in effective regulation. Awarding a WEGA seal of approval can been viewed as giving tacit government approval of PMI's business. The post that linked to ABF supported July 2019 policy changes that require all Australian tobacco importers to be licensed. PMI states it supports this policy as it will, "make it easier to prosecute those involved with illegal tobacco trade," positioning itself as a good corporate partner to government. Linking to government sources or departments in this way adds legitimacy to PMI's online activities by helping the company appear as an acceptable partner in policy making.

$\mathrm{PMI}$ has also used the Facebook page to increase the visibility of its executive employees, marking a sharp change in its public relations approach which saw little public comment from senior staff in the previous decade. For example, a profile article ${ }^{11}$ on Tammy Chan, Managing Director PMI Australia, that was published in the Australian Financial Review, was shared on the page. The post highlighted the company's claimed rationale for a smoke-free future as, "let's not wait for someone like Amazon to disrupt us like they have the retail sector. Let's disrupt ourselves." And yet PMI continues to aggressively market and sell its flagship cigarette brand, Marlboro, particularly in low- and middle-income countries.

\section{Conclusion}

This analysis suggests that PMl is using its Australian Facebook feed primarily in an effort to weaken Australian tobacco control laws. Despite claims that it is being 'disruptive', this strategy is near identical to previous efforts to weaken health regulations and gain a seat at the policy table. ${ }^{5}$

\section{Acknowledgements}

BF has received research grants from the Australia Indonesia Centre and Australian Government during the conduct of this study. Outside the submitted work, she reports grants from Australian Government Department of Health, NSW Department of Health, Cancer Institute 
NSW and National Health and Medical Research Council and has received personal fees from WHO, Asian Center for WTO \& International Health Law and Policy, National Taiwan University, College of Law and from Department of Health The Government of Hong Kong Special Administrative Region.

$\mathrm{MH}$ reports research grants from the Heart Foundation and National Health and Medical Research Council, consultancy fees from Taiwan Medical University to speak at the National Tobacco Conference and an honorarium from BMJ Tobacco Control journal.

\section{Peer review and provenance}

Externally peer reviewed, invited.

\section{Competing interests}

None declared.

\section{Author contributions}

All authors contributed to the study concept, interpreting the findings and writing the manuscript. BF collected and analysed the data and wrote the first draft of the paper.

\section{References}

1. World Health Organization. WHO Framework Convention on Tobacco Control. Geneva: WHO; 2003 [cited 2019 Aug 29]. Available from: apps.who.int/iris/bitstream/ handle/10665/42811/9241591013. pdf;jsessionid=09F1B4 7FB11DB74720A031FAC3080258?sequence $=1$

2. Watts $\mathrm{C}$, Hefler M, Freeman B. 'We have a rich heritage and, we believe, a bright future': how transnational tobacco companies are using Twitter to oppose policy and shape their public identity. Tob Control. 2019;28:227-32.
3. Legg T, Peeters S, Chamberlain P, Gilmore AB. The Philip Morris-funded Foundation for a Smoke-Free World: tax return sheds light on funding activities. Lancet. 2019;393(10190):2487-8.

4. Philip Morris International. Neuchâtel, Switzerland: Philip Morris Products S.A. Taking e-cigarettes further: e-vapor products [about 2 screens]; [cited 2019 Aug 27]. Available from: www.pmi.com/smoke-free-products/meshtaking-e-cigarettes-further

5. Bialous SA, Glantz SA. Heated tobacco products: another tobacco industry global strategy to slow progress in tobacco control. Tobacco control. 2018 Nov 1;27(Suppl 1):s111-7.

6. Bialous SA. Impact of implementation of the WHO FCTC on the tobacco industry's behaviour. Tobacco Control. 2019;28(Suppl2):s94-96.

7. Philip Morris International. Social media rules of engagement. Melbourne, VIC: PMI; updated 2019 March 23 [cited 2019 September 3]. Available from: bit.ly/2HzfF6x

8. Philip Morris International. @PhilipMorrisAustralia Facebook page. Menlo Park, CA: Facebook; [cited 2019 Sep 4]. Available from: www.facebook.com/ PhilipMorrisAustralia/?brand_redir $=883165171742476$

9. Harper T. Why the tobacco industry fears point of sale display bans. Tob Control. 2006;15:270-1.

10. Institute for Global Tobacco Control. Country laws regulating e-cigarettes. Baltimore, MD: Johns Hopkins Bloomberg School of Public Health; updated 2018 Nov 2 [cited 2019 Aug 27]. Available from: www.globaltobaccocontrol.org/e-cigarette/sale

11. Durkin P. Philip Morris boss Tammy Chan is disrupting her own business. Sydney: Financial Review; 2018 Jun 7 [cited 2019 Aug 29]. Available from: www. afr.com/workand-careers/management/philip-morris-boss-tammychan-is-disrupting-her-own-business-20180511-h0zyvt

\section{Copyright: (ㄷ) (i) (2) (2)}

(C) 2019 Freeman et al. This article is licensed under the Creative Commons Attribution-NonCommercial-ShareAlike 4.0 International Licence, which allows others to redistribute, adapt and share this work non-commercially provided they attribute the work and any adapted version of it is distributed under the same Creative Commons licence terms. See: www.creativecommons.org/licenses/by-nc-sa/4.0/ 